\title{
HERNÁN CORTÉS Y LAS MUJERES: VIDA Y POESÍA
}

A mi hija Marina Elizabeth

Nadie ignora que Hernán Cortés fue tan emprendedor y tan afortunado en las lides amorosas como en las militares. Acudiendo a las fuentes históricas de los siglos xvi y xvn, trataré de precisar aquí lo que se sabe de las mujeres que entraron en su azarosa vida y del trato que tuvo con ellas, y procuraré aclarar ciertos detalles biográficos que muchas veces han dado pie a ásperas censuras morales. Me propongo asimismo estudiar un tema más novedoso y virgen: la proyección literaria de este aspecto de la vida de Cortés en la poesía española del Siglo de Oro.

Fue Cortés, según Gómara, "muy dado a mujeres, y diose siempre"'. Y en efecto, este historiador se complace, a través de su obra, en narrar los muchos lances de amor cuyo protagonista fue nuestro héroe, tanto en España como en las Indias (uno de ellos, el movido episodio del escalamiento de tapias ajenas, que retardó la salida del joven Hernando para el Nuevo Mundo).

También Bernal Díaz atestigua este rasgo, y no sin cierto resentimiento en una ocasión, cuando cuenta cómo, tras una batalla, Cortés y sus capitanes "habían ya escondido y tomado las mejores indias, que no apareció allí ninguna buena, y al tiempo de repartir dábannos las viejas y ruines", de manera que "sobre esto hubo muy grandes murmuraciones" contra él ${ }^{2}$.

Después de la conquista, según los que declararon en el "juicio de residencia" de Cortés, hubo en su casa, constantemente, gran número de mujeres, así indias como españolas ${ }^{3}$. Los testimonios

1 Francrsco López de Gómara, Historia de la conquista de México, ed. J. Ramírez Cabañas, México, 1943, t. 2, p. 298. Esta edición reproduce la primera, de 1552 . Es significativo que las palabras citadas hayan sido suprimidas en las ediciones posteriores, a partir de la de 1554 .

2 Bernal Díaz del Castillo, Historia verdadera de la conquista de la Nueva España, ed. de París, 1936-37, cap. 135 (t. 2, pp. 240-241).

3 Sumario de la residencia tomada a D. Fernando Cortés, gobernador y capitán general de la Nueva España, y a otros gobernantes y oficiales de la misma (1529), ed. paleográfica de I. López Rayón, en los Documentos para la historia de México, México, 1852, t. 1, pp. 62-63, 98-99, 123, 159, 202-203, 
son sin duda exagerados: además de basarse en hablillas, casi todos los testigos estaban descontentos de Cortés o incluso tenían alguna querella personal contra él, y esta predisposición era justamente lo que los llevaba a declarar ante los jueces. La historiadora mexicana Eulalia Guzmán, empeñada como está en pintar a Hernán Cortés como el mayor bribón del mundo, acepta sin embargo esos dudosos testimonios como verdad inconcusa, y habla de la "lujuria sin escrúpulos" del conquistador, que "burló mujeres a pasto" ${ }^{4}$. En todo caso, cabría replicar que Cortés no tenía votos de castidad, y que en la España de la época estaba perfectamente reconocida y aceptada la institución de la barraganía ${ }^{5}$.

Recordemos, por último, que Cortés dejó una estela de hijos naturales, y que mostró por ellos verdadero amor y gran sentido de responsabilidad ${ }^{6}$.

Con los éxitos amorosos tiene que ver el aspecto físico del hombre. Por desgracia, no sabemos con seguridad absoluta cómo era Hernán Cortés. No se ha demostrado, hasta la fecha, la autenticidad de ninguna de las treinta y tres representaciones (retratos y medallones) que se conservan, por mucho que los diversos comentaristas iconográficos se esfuercen en hacer triunfar sus respectivas teorías ${ }^{7}$.

$263-264,337,383-384,415 ;$ t. 2, pp. $39,70,101-102,117,194,158,196-197,216$ (contestaciones a la pregunta 39 ). La crítica principal de la mayoría de estos testigos es que a menudo las mujeres tenían parentesco entre sí hasta el cuarto grado. Según un testigo (t. 1, p. 159), Cortés tenía relaciones carnales nada menos que con cuarenta indias a la vez.

4 Eulalia Guzmán, "Prólogo" a su ed. de las Relaciones de Hernán Cortés a Carlos $V$ sobre la invasión de Anáhuac: aclaraciones y rectificaciones, México, 1958, t. 1, pp. c-ci.

5 S. de Madariaga, Hernán Cortés, Buenos Aires, 1941, pp. $210-211$.

6 Además de recordarlos generosamente en su testamento, obtuvo una bula extraordinaria (Roma, 16 de abril de 1529) que hacía legítimos a Martín Cortés (hijo de doña Marina), a Luis Altamirano (nacido en México de madre española, Antonia Hermosilla) y a Catalina (hija de una india cubana). En un documento fechado en Colima a 9 de enero de 1535 menciona Cortés a esos tres y a otras dos hijas naturales, María y Lconor, a propósito de la herencia de sus bienes (cit. por A. López de Meneses, RIM, 9, 1948, p. 482). El conquistador hizo los arreglos necesarios para el matrimonio de Leonor (cf. infra, nota 43) y para el de otras hijas. Cf. las palabras de un orgulloso descendiente de Cortés, Federico Gómez de Orozco, Doña Marina, la dama de la conquista, México, 1942, p. 197: "quien haya estudiado el carácter de Cortés, sabe que una de sus más gratas satisfacciones fue la de sentirse padre... Por eso nunca rehusó reconocer y recoger a los hijos numerosos que su azarosa vida le deparó a lo largo de la ruta de sus andanzas".

7 Citaré algunos: Manuel Romero de Terreros, Los retratos de Hernán Cortés. Estudio iconográfico, México, 1944; Manuel Toussaint, "El criterio artístico de Hernán Cortés", $E A, 1$ (1948), 70-78; JEAN M. Babelon, "Un retrato verdadero de Hernán Cortés", Memorias de la Acad. Mex. de la Hist., 
Pero si los dos óleos que se conservan en el Hospital de Jesús de la ciudad de México no son, evidentemente, verdaderos retratos, sino figuraciones idealizadas del prototipo 'anciano noble', con mayor convicción aún hemos de rechazar la representación ideada por Diego Rivera en uno de sus murales del Palacio Nacional de México, de acuerdo con una fuente indigenista, la llamada Tradición de Ixcateopan (apud Eulalia Guzmán, "Prólogo" cit., p. xxxviii), según la cual Cortés "era feo, bajo, desfigurado, apestoso, un pedazo de hombre". No sé hasta qué punto pueda decirse que esta absurda versión sea la "oficial" en México (día tras día, millares de inocentes turistas, de pie ante la genial caricatura que aparece en ese mural, oyen decir a los guías que Cortés fue tal como lo pintó Diego Rivera, por más que a menudo surja de entre los espectadores alguna voz, sobre todo femenina, que pregunta cómo es que un monstruo tan deforme y horripilante pudo merecer los favores de ninguna mujer). Pero doña Eulalia Guzmán, que ocupa en el Museo Nacional un puesto oficial, el de historiógrafa, sostiene la veracidad de la Tradición de Ixcateopan y aprueba el "retrato" de Rivera, igual que las imágenes no menos desfavorables de Cortés que figuran en el Lienzo de Tlaxcala y en el Códice florentino. Su apasionada "conclusión diagnóstica" (ibid., pp. lxxxii-xciv), es que Cortés sufrió un enanismo desfigurante, causado por sífilis congénita del sistema óseo, y se empeña largamente en demostrarlo con los datos que le ofrecen los supuestos huesos de Cortés. Hay, desgraciadamente, otros mexicanos "revolucionarios" que empobrecen su criterio al perpetuar tales disparates ${ }^{8}$. Y el México revolucionario $-o$, para decirlo con mayor precisión, el sector de él representado ahora por doña Eulalia-, al vilificar a Cortés en su ansiosa búsqueda de una identificación con el pasado indígena, ha impuesto, como es bien sabido, una especie de anatema contra la exhibición pública de cuadros o estatuas que puedan tender a glorificar al conquistador'.

I3 (1954), I73-178; Carmelo SÁenz de Santa María, "Iconografía cortesiana. (Hacia la identificación de su verdadero retrato)", $R I M$, i 8 (1958), 541-560. El "Inventario de los bienes de D. Martín Cortés", publ. en los Documentos inédilas relativos a Hernán Cortés y su familia, México, 1935, p. 423, menciona "El retrato del Marqués don Hernando Cortés", del cual dice el editor, Rafael López, que era "probablemente el primero y más auténtico" (p. ix).

8 Véanse, como ejemplo, las palabras del general RubÉN García, "La esplendorosa belleza de la emperatriz Tecuichpo, sus célebres amores con príncipes mexicanos y magnates españoles", en el Magazin Dominical de los Periódicos Lozano, 27 de nov. de 1955, p. 9: “...pero llegó el diablo en forma de enano patizambo, pues como se sabe, Hernán Cortés padecía "enanismo sifilitico" y era cascorvo".

- Por ejemplo, Toribio Esouivel Obregón, en la Introducción de su libro Hernán Cortés y el derecho internacional en el siglo xvi, México, 1930, pp. 
¿Qué dicen de Hernán Cortés los españoles que lo conocieron personalmente? Era, dice Gómara al final de su historia (t. 2, p. 298), "de buena estatura, rehecho y de gran pecho; el color ceniciento, la barba clara, el cabello largo. Tenía gran fuerza, mucho ánimo, destreza en las armas". Y Bernal Díaz (cap. 204: t. 4, pp. 159-160): "fue de buena estatura y cuerpo, y bien proporcionado y membrudo, y la color de la cara tiraba algo a cenicienta, e no muy alegre; y si tuviera el rostro más largo, mejor le pareciera; los ojos en el mirar amorosos, y por otra graves; las barbas tenía algo prietas y pocas y rasas, y el cabello que en aquel tiempo se usaba era de la misma manera que las barbas, y tenía el pecho alto y la espalda de buena manera, y era cenceño y de poca barriga y algo estevado, y las piernas y muslos bien sacados". Ni enano, ni cascorvo, ni deforme. Cervantes de Salazar agrega que Cortés era "de buen rostro"10. Los tres cronistas citados son los únicos que nos han dejado un retrato vivo, basado en su conocimiento directo. Se ve que sus descripciones no se refieren a los años juveniles ni anteriores a la conquista, cuando el conquistador debió de ser aún mejor parecido.

Evidentemente, Cortés era más bien guapo que feo, y ejercía una poderosa atracción masculina sobre las mujeres.

Examinemos ya a esas mujeres que desempeñaron un papel en la vida de nuestro personaje.

Pocos años después de su venida de España, el joven Cortés, siendo un hacendado rico en Cuba, tuvo un enredo amoroso que fue la causa de que el gobernador Velázquez lo hiciera víctima de fuertes persecuciones. Pondera Gómara (t. 1, p. 47) la escasez de mujeres españolas en la isla, y la natural popularidad de que allí gozaron unas hermanas Juárez, pobres pero "bonicas". Una de ellas, Catalina, atrajo las miradas de Cortés, quien la festejó y la ganó para sí. Más tarde se quejó ella formalmente - no sabríamos decir si con justificación o no- de que Cortés le había dado su palabra de casamiento y se negaba a cumplírsela. A la sazón andaba el gobernador Velázquez tras una de las hermanas de Catalina, y decidió por lo tanto tomar cartas en el asunto. Añade Gómara que esa hermana tenía "ruin fama", y que Velázquez era "demasiado mujeril". Como dice Pereyra, "parece que toda la razón estaba de parte del que rechazaba la demanda [o sea Cortés], pues Velázquez no tenía autoridad para formularla, ya que la ruin fama de su favorita, y su propia conducta, lo incapacitaban como censor de cos-

7-55, describe con indignación su lucha inútil para que el gobierno le diera permiso de colgar un retrato de Cortés en la Sociedad Mexicana de Geografía y Estadística, de la que él era presidente.

10 Francisco Cerrvantes de Salazar, Crónica de la Nueua España, Madrid, 1914, p. 99 . 
tumbres y defensor de doncellas engañadas"11. Cuenta Bernal Díaz (cap. 19: t. 1, p. 77): "sobre este casamiento de Cortés le sucedieron muchas pesadumbres y prisiones; porque Diego Velázquez favoreció las partes d'ella, como más largo contarán otros". Al final, Cortés optó por casarse con Catalina, y así volvió a disfrutar del favor del gobernador, detalle importante para que a la larga se le diera el mando de la expedición a México. Bernal Díaz (cap. 20: t. 1, p. 79) nos dice que el propio Velázquez apadrinó la boda.

Un año después de la conquista, llegó inesperadamente Catalina Juárez a México, acompañada de su hermano y de otros parientes, para reunirse con su ya famoso marido. Aquí se calla Gómara, pero Bernal Díaz (cap. 16o: t. 3, p. 16o) nos informa lacónicamente: "cuando Cortés lo supo, dijeron que le había pesado mucho de su venida, puesto que [='aunque'] no lo demostró y les mandó salir a recebir; y en todos los pueblos les hacían mucha honra, hasta que llegaron a México, y en aquella ciudad hubo regocijos y juego de cañas; y dende a obra de tres meses que hubieron llegado oímos decir que esta señora murió de asma”.

Las circunstancias de la muerte de Catalina - unidas a las noticias que se tenían sobre su índole celosa y oportunista- dieron origen a la sospecha de que él la había estrangulado. Según un testimonio del iuicio de residencia, Catalina provocó una escena violenta en una fiesta que dio Cortés aquella noche trágica ${ }^{12}$, al acusar públicamente a Francisco de Solís de ocupar a los indios de ella en ciertos trabajos sin su permiso; Solís le dijo que era Cortés quien así los ocupaba, y Catalina, enojada, le contestó: "Yo vos prometo que antes de muchos días haré yo de manera que no tenga nadie que entender con lo mío", a lo cual replicó Cortés: "Con lo vuestro, señora, yo no quiero nada de lo vuestro". La amenaza de Catalina pudiera ser una velada alusión a las otras mujeres que había en la vida de su marido, y la respuesta de él una franca expresión de su desprecio.

Pocas horas después de la fiesta, de repente fue despertada la casa por las voces del dueño, que gritaba que su mujer parecía estar muerta en la cama (y, según el rumor que en seguida comenzó a

11 Carlos Pereyra, Hernán Cortés, Buenos Aires, 1953, p. 32. Según Gonzalo de Illescas, en un pasaje de su Historia pontifical reprod. en apéndice a la crónica de Argensola, ed. Ramírez Cabañas, p. 273 (cf. infra, nota 27), y Prudencio de Sandoval, Historia de la vida y hechos del emperador Carlos $V, B A E$, t. 80 , p. 164 , Cortés no tenía intenciones de casarse con Catalina, sino que sólo quería tenerla de amiga.

12 Sumario cit., t. 2, pp. 364-366, pormenores dados por el testigo Isidro Moreno. Otro testigo, la criada Ana Rodríguez (ibid., p. 353), ya había comentado que Catalina era celosa, "por que el dicho D. Fernando festejaba damas e mugeres que estaban en estas partes". 
correr, con la garganta llena de cardenales, y las cuentas de un collar esparcidas por el suelo). Otro hecho contribuyó a excitar la fantasía popular en torno a la escena nocturna: a la criada Violante Rodríguez se le ocurrió comentar que doña Catalina había muerto "como la mujer del conde Alarcos"13.

El cronista Suárez de Peralta, sobrino, por cierto, de Catalina Juárez, declara que esta señora murió después de un agudo dolor de vientre y a consecuencia de un ataque de "mal de madre" - del cual dice que fallecieron en México otras hermanas de Catalina-, y afirma que las acusaciones criminales son "maldad grandísima levantada de malos hombres, los cuales creo y tengo por muy cierto lo han pagado o pagan en el otro mundo"14. El proceso formal por uxoricidio que se levantó a Cortés terminó con una sentencia absolutoria, pero aún hoy se sigue discutiendo el asunto ${ }^{15}$.

En la proyección literaria de la vida del conquistador, la única versión que toca el tema de la muerte de Catalina es la anónima Comedia de los pleytos de Hernando Cortés de Monroy (ms. 18.085 de la B.N.M., del siglo xvn), la cual evita cuidadosamente toda complicación. En la jornada I, el conquistador, antes libertino y ahora trágico, le cuenta a Carlos V:

Caséme con vna dama,
de moçedades cansado,
honrada y pobre, qu'el noble
no busca más aparato.
Murió estando en la conquista,
mi ausencia triste llorando;
qu'el que mujer vuena pierde,
pierde su gloria y descanso.

Nos informa Gómara (t. 2, pp. 187-188) que tan pronto como se supo en España la noticia de que Cortés había enviudado, muchos

13 Sumario, t. 2, p. 362. En el conocido romance, el conde, después de asesinar a la condesa, "levantóse dando voces / a la gente que tenía. / - iSocorred, mis caballeros, / que la condesa se fina!"

14 Juan Suárez de Peralta, Tratado del descubrimiento de las Indias. (Noticias históricas de Nueva España), México, 1949, pp. 76-77.

15 Véase el "Proceso criminal de María de Marcayda [madre de Catalina] contra D. Fernando Cortés", en el Sumario cit., t. 2, pp. 333-375. Hay más testimonios sobre el asunto en otras secciones del Sumario, v.gr. t. 1, pp. $159^{-}$ 161, y t. 2, pp. 251-252. -Para la discusión entre los historiadores madernos, cf. Francisco Fernández del Castillo, Doña Catalina Xuárez Marcayda, primera esposa de Hernán Cortés, y su familia, México, 1920; Ángel D: Alto laguirre, "Prueba histórica de la inocencia de Hernán Cortés en la muerte de su esposa", BAH, 76 (1920), 105-110; Zelia Nuttall, "Algunos datos sobre Hernán Cortés y su primera esposa doña Catalina Xuárez", Memoria y Revista de la Sociedad Científica "Antonio Alzate", México, 39 (1921), 125-135; ALFonso Toro, Un crimen de Hernán Cortés: la muerte de doña Catalina Xuárez 
quisieron conseguirlo para esposo de alguna hija o parienta, pues la fama y la riqueza del conquistador hacían de él un excelente partido. Don Álvaro de Zúñiga, duque de Béjar, actuó "con mucho calor" en favor de su sobrina Juana de Zúñiga, hija del conde de Aguilar, y pronto se llegó a un acuerdo a través de ios poderes que llevaba don Martín Cortés, padre de nuestro héroe. Según el mismo Gómara, Juana era hermosa y su familia gozaba de gran influencia ante el emperador. Agrega Bernal Díaz (caps. 170 y 171: t. 3 , pp. 258 y 264 ) que, a resultas del contrato de matrimonio, el duque de Béjar def́endió con eficacia los intereses de Cortés en la corte, aunque más adelante (cap. 195: t. 4, p. 107) expresa la opinión personal de que hubiera sido más ventajoso para su capitán casarse con la cuñada del comendador mayor de León, que era otra de las interesadas. En todo caso, al volver triunfante a España en 1528 , Cortés ya se daba por casado de nuevo.

Claro que los matrimonios de conveniencia, arreglados de antemano sin que a veces se conocieran los novios, eran la regla de entonces, pero el gusto popular exigía que el héroe conquistara la voluntad de la dama en forma romántica. Dos comedias del siglo xvIr pretenden satisfacer ese gusto. Al levantarse el telón en $E l$ valeroso español y primero de su casa, de Gaspar de Ávila (BAE, t. 63), doña Juana lamenta la decisión de su abuelo, el duque, de llevarla a la corte para casarla. La escena transcurre en Sanlúcar, donde ella vive feliz desde el fallecimiento de su madre. Mujer de carácter voluntarioso, sueña con un soldado fuerte, y no con un cortesano cualquiera (p. $\left.5^{6} 3\right)$ :
Tengo un alma belicosa, y no soy para casada; y una vez determinada, Leonor, a tomar estado, antes quisiera un soldado valiente por su persona, que la más digna corona que a humanas sienes se ha dado.

En ese preciso momento llega el fuerte y bizarro Cortés. A doña Juana le basta contemplarlo para rendirle al punto el alma (p. 568).

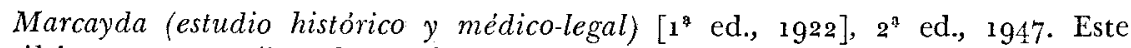
último presenta "pruebas objetivas y científicas" de que Cortés asesinó a su mujer, si bien suaviza su juicio con la consideración de que ello no era en la época tan reprobable moralmente como lo sería hoy. Pererra, op. cit., p. 233, sostiene que la acusación de uxoricidio es calumniosa y absurda: "el imaginario crimen sólo podría explicarse como un arrebato pasional, incomprensible en un hombre como Cortés, todo reflexión cuando se veía contrariado y hasta ultrajado, o como un siniestro cálculo, que hubiera tenido mil medios de ejecutar sin que recayese sobre él sospecha alguna'. 
Apenas a Cortés vi, cuando en el alma sentí, asida a mi inclinación, una blanda sujeción a que no me defendí; y yo tan sin mí quedé que aun de mí misma no sé.

Un intercambio de regalos - un "gracioso" por una india- da ocasión para que los enamorados se vean. Al acercarse la cita, se asombra Montejo, compañero de Cortés (p. 569 ): “¿De una mujer/tiembla el que ha vencido ya / de todo el mundo el poder?" $\mathrm{Y}$ el indomable capitán, que es también enamorado discreto, le responde:
Sí, que en esta guerra está
la valentía en temer, y en un triunfo voluntario, será favor conocido, que exceda de lo ordinario, darse un hombre por vencido cuando es mujer el contrario.

El acto II muestra a un Cortés que desesperadamente hace frente a los enemigos envidiosos de la corte, mientras doña Juana intercede por él. Y en el acto III, doña Juana sorprende a todos al descubrir abiertamente su pasión: "Deciros quisiera ahora / mi fe, mi amor, mi lealtad,/mi resuelta voluntad" (p. 576). En verdad, la respuesta de Cortés es bastante tibia. (Hay que reconocer que Gaspar de Ávila parece haberse interesado más por la figura voluntariosa de la dama que por la del conquistador). Al final, Carlos V bendice la unión, tras preguntar a Juana si quiere casarse con Cortés (a éste no se lo pregunta).

Algo más femenina se nos muestra Juana en la Comedia de los pleytos. Antes hemos visto cómo deplora Cortés, en esta obra anónima, la muerte de su amada Catalina. Carlos V colma de favores al afligido, cuando de pronto irrumpe en la escena la desconocida doña Juana, que, más atribulada aún, viene llorando a su padre, muerto en servicio del rey, en guerra contra el turco. "¿Adónde me e de amparar?" -exclama-; “quién en el suelo español / remedio me podrá dar?” (jornada I). El emperador socorre a la acongojada doncella, nueva Ximena, poniéndola bajo el amparo de Cortés. Éste se muestra entonces alegre, como un nuevo Cid mozo, e inmediatamente el Emperador manda que el arzobispo los case. La jornada II muestra a Cortés en la cárcel, cargado de cadenas, y a Juana que se pasea por el escenario, llena de angustia: "bengo buscando a mi esposo, / qu'es el pastor de mi alma”. Cuando se reúnen los dos, él 
le dice a Juana que su presencia ha aliviado el rigor de la cárcel, "que no ay cosa más lijera / que las prisiones de amor".

Es probable que La conquista de Cortés o El Marqués del Valle, comedia perdida de Lope de Vega, haya tenido como tema central la conquista del amor de Juana por Hernán Cortés ${ }^{16}$.

Los poemas épicos de Lasso, publicados en fechas anteriores a las obras teatrales que hemos recordado ${ }^{17}$, y cuya orientación genérica es bien distinta de la de las comedias, mencionan brevemente a Juana. En la Mexicana (fol. 112), el río Tabasco le vaticina a Cortés, en sueños, que será ella su esposa. La misma predicción se pone en el Cortés valeroso (fol. 168) en boca de la ninfa Calianera:

$$
\begin{aligned}
& \text { Casarás con la bella doña luana } \\
& \text { de Cúñiga, donzella virtuosa, } \\
& \text { discreta, afable, jouen y loçana, } \\
& \text { dispuesta, graue, y en estremo hermosa. }
\end{aligned}
$$

Entre las amantes de Cortés, ninguna, por supuesto, más famosa que doña Marina, la Malinche ${ }^{15}$. Fue una de las veinte mujeres que los caciques dieron al capitán español en Tabasco, en $15^{19}$, y él se la asignó a su amigo Portocarrero. En Chalchiucuecan, cerca de lo que hoy es Veracruz, se descubrió que Marina era, en el grupo español, la única persona que sabía náhuatl. De allí en adelante se convirtió en la leal intérprete de Cortés, a través de Jerónimo de Aguilar: ella traducía del náhuatl al maya, y él del maya al español, hasta que, con el tiempo, aprendió ella misma el español.

Tres meses después de distribuir a las veinte indias entre sus hombres, Cortés despachó a Portocarrero a España como embajador ante Carlos V. No falta hoy quien crea que lo hizo con el intento calculado de quedarse con doña Marina, cuando en realidad eligió sin duda a Portocarrero por las influencias que tenía en España. En todo caso, ausente Portocarrero, Cortés se quedó en efecto con

10 Véase Wrlliam I. Frchter, "Lope de Vega's La conquista de Cortés and El Marqués del Valle", HR, 3 (1935), 169-165, sobre la cuestión de si se trata de una sola comedia con dos títulos, y Marcos A. Morínigo, América en el teatro de Lope de Vega, Buenos Aires, 1946, pp. 230-231, sobre la probabilidad de que la "conquista" haya sido la de Juana y no la de México.

if Gabriel [Lobo] Lasso DE LA VEga, Cortés valeroso y Mexicana, Madrid, 1588 ; Mexicana, Madrid, 1594.

is Malinche es corrupción hispanizada del nombre indio Malintzin (el sufijo reverencial tzin equivale a doña). Véanse, entre otros, los siguientes estudios: Joaquín García Icazbalceta, "Doña Marina", en sus Obras, t. 4, México, 1897, pp. 13-15; Hubert H. Bancroft, History of Mexico, San Francisco, Calif., 1883-88, t. 1, pp. 1 10-1 20; Pereyra, p. 83; C. SEco, "Doña Marina a través de los cronistas", RIM, 9 (1948), p. 498, nota 5 ; y sobre todo Gustavo A. Rodríguez, Doña Marina, México, 1935, pp. 3-5. 
ella. Esto ocurrió en julio de 1519 . Así, pues, doña Marina sirvió de continuo hasta que en 1524 Cortés se la entregó como esposa al soldado Juan Jaramillo ${ }^{19}$, con el cual pasó el resto de su vida, respetada y rica, en la capital de la Nueva España ${ }^{20}$.

La cuestión del lugar de nacimiento de esta mujer, y de las circunstancias que la llevaron a conocer los idiomas náhuatl y maya, ha recibido diversas explicaciones. Según Gómara (t. 1, p. 105), Marina "dijo que era de hacia Xalisco, de un lugar dicho Viluta, hija de ricos padres, y parientes del señor de aquella tierra; $y$ que siendo muchacha la habían hurtado ciertos mercaderes en tiempo de guerra, y traído a vender a la feria de Xicalanco, que es un gran pueblo sobre Coazacualco, no muy aparte de Tabasco". Otros historiadores que afirman que doña Marina era natural de Jalisco (región donde en efecto se hablaba el náhuatl) son Las Casas, Landa, Herrera y Torquemada ${ }^{21}$. Oviedo y Muñoz Camargo aceptan que fue hurtada por mercaderes del sur, pero no que su lugar de origen fuera Jalisco ${ }^{22}$. La versión que da Bernal Díaz (cap. 37: t. 1, p. 132) es algo distinta:

... su padre y su madre eran señores y caciques de un pueblo que se dice Painala, y tenía otros pueblos sujetos a él, obra de ocho leguas de la villa de Guacaluco, y murió el padre quedando muy niña, y la madre se casó con otro cacique mancebo y hobieron un hijo, y, según pareció, querían bien al hijo que habían habido; acordaron entre el padre y la madre de dalle el cargo después de sus días, y porque en ello no hubiese estorbo, dieron de noche la niña a unos indios de Xicalango, por que no fuese vista, y echaron

19 Existe una "Relación que dio el capitán Juan Jaramillo de la jornada que hizo a la tierra nueva [el norte de México], de la cual fue general Francisco Vázquez de Coronado" (1542), publ. en la Colección de varios documentos para la historia de la Florida, Londres-Madrid, 1857 , t. 1, pp. 154-163.

20 No están de acuerdo los historiadores en cuanto al año de su muerte. Se había venido creyendo que aún vivía en $155^{\circ}$ (BANcrort, t. 1, p. 120, nota 6), o al menos en 1547 (G. A. Rodrícuez, p. 42), pero Gómez de Orozco, Doña Marina, p. 190, nota 9 , ofrece argumentos convincentes para probar que murió en ${ }^{1531}$ (su principal argumento es que Juan Jaramillo volvió a casarse en 1532). Henry R. Wagner, The rise of Fernando Cortés, Los Angeles, 1944, cap. 5 "Doña Marina", pp. 68-79, ofrece abundantes referencias históricas y dice que probablemente ya había muerto en 1529 .

21 Bartolomé de las Casas, Historia de las Indias, México, 1951, t. 3, p. 244; Diego De LANDA, Relación de las cosas de Yucatán [1566], ed. H. Pérez Martínez, México, 1938, p. 67; Antonio de Herrera y Tordesillas, Historia general de los hechos de los castellanos en las islas y tierra firme del Mar Océa no, Madrid, 1934-55, t. 4, p. 377; JUAN DE ToRquemadA, Monarquia indiana, México, 1943, t. 1, p. 388 .

22 Gonzalo Fernández de Oviedo, Historia general y natural de las Indias, islas y tierra firme del Mar Océano, Madrid, 1851-55, t. 3, p. 259; Dieco MuÑoz Camargo, Historia 'de Tlaxcala, ed. A. Chavero, México, 1892, p. 179. 
fama que se había muerto, y en aquella sazón murió una hija de una india esclava suya, y publicaron que era la heredera, por manera que los de Xicalango la dieron a los de Tabasco, y los de Tabasco a Cortés...

Los historiadores de hoy aceptan, en general, la versión de Bernal Díaz $^{23}$. Parece, pues, que doña Marina nació en algún lugar de lengua náhuatl hacia el sur, y no en Jalisco, puesto que Bernal Díaz relata cómo, después de la conquista, él conoció personalmente a su madre y a su medio hermano en la provincia de Coatzacoalcos ${ }^{24}$, y que la madre le aseguró que de allí eran (cap. 37: t. 1, p. 193).

Cervantes de Salazar (p. 1 g6) prefiere una variante dudosa: que el padre de doña Marina era el cacique de Totiquipaque, que la madre era una de sus esclavas, y que allí fue robada la muchacha. Sea cual sea la verdad última, el hecho es que las mocedades de doña Marina fueron tan llamativamente novelescas, que se identificaron fácilmente con las fantasías absorbidas por la conciencia española a través de los libros de caballerías ${ }^{25}$.

Otros autores agregan detalles nacidos de la ignorancia o de la pura y simple imaginación. Supone Durán que antes de la llegada de Cortés ya sabía doña Marina el español y el náhuatl, y que había servido de intérprete a la expedición de Grijalva el año anterior ${ }^{26}$. Según Argensola, creían los mexicanos que ella hablaba náhuatl por revelación divina de los españoles, a quienes ellos consideraban dioses $^{27}$. Y Suárez de Peralta (p. 39) cuenta que doña Marina se

${ }^{23}$ Cf. William H. Prescott, History of the conquest of Mexico, Philadelphia, 1873, t. 1, pp. 292-293; García ICAZbalceta, pp. 5-10; BanCrofT, t. 1, pp. 118-119; Pereyra, p. 83; Gómez de Orozco, pp. 9 ss.; G. A. Rodríguez, pp. 11-15. Diego López Gogolludo, Historia de Yucatán, Campeche, 1954-55, t. 1, p. 124, acepta la versión de Bernal Díaz y agrega que la "esclavitud penosa" de doña Marina fue permitida por la Divina Providencia, justamente por el bien que iba a reportar su preparación lingüística.

${ }_{24}$ Cf. G. A. Rodríguez, p. 15, donde se concluye, tras una larga argumentación, que doña Marina nació en el pueblo de Oluta, en el actual municipio de Coatzacoalcos (Estado de Veracruz).

${ }_{25}$ Leonardo Olschi, Storia letteraria delle scoperte geografiche, Firenze, 1937, cap. 3, hace algunos luminosos comentarios sobre cómo el recuerdo de los libros de caballerías llevó a Bernal Díaz y a otros cronistas a engrandecer el papel de doña Marina como heroína de la conquista. (Cit. por StePHeN Gilman, "Bernal Díaz del Castillo and Amadis de Gaula", $H D A$, t. 2, p. 114, nota 26 ).

26 Diego Durán, Historia de las Indias de Nueva España y islas de tierra firme [1581], México, 1951, t. 2, p. 18.

27 Bartolomé Leonardo de Argensola, Conquista de México (Primera parte de los Anales de Aragón), ed. J. Ramírez Cabañas, México, 1940, p. 119. Cervantes de Salazar, p. 136, dice que si doña Marina no traicionó a los españoles, fue por una iluminación de Dios, idea acogida con entusiasmo por C. SEco, art. cit., p. 503: “¡Alumbrada por Dios! ¿No será, en efecto, éste el 
encontraba por casualidad en el sur cuando llegó Cortés, porque acompañaba a un capitán azteca mandado por Moctezuma para castigar a un cacique de allí; cumplida ya la misión (con el envío de la cabeza del cacique al emperador), doña Marina había consentido en guiar a los españoles en su viaje a Tenochtitlán ${ }^{28}$. La Malinche fue una leal servidora de Moctezuma, pero también afirma Suárez de Peralta que tuvo seis hijos de Cortés, lo cual es sencillamente imposible ${ }^{29}$.

Algunos autores de la época creyeron mejor eliminar toda tacha moral de su retrato del caudillo. Así, Muñoz Camargo dice que doña Marina y Jerónimo de Aguilar se conocieron y se casaron aun antes de que Cortés pisara las costas mexicanas ${ }^{30}$. Illescas e Ixtlilxóchitl no llegan a tanto, pero afirman que se casaron poco después ${ }^{31}$. Este imaginario suceso se dramatiza románticamente en la comedia La conquista de México, de Fernando de Zárate ${ }^{32}$. Sus tiernos votos de matrimonio son bendecidos por Cortés al día si. guiente del descubrimiento y del bautismo de ella. La unión de

secreto...? La luz divina ha llegado ya al fondo de su alma, ingenua y primitiva", etc., etc.

28 HiLde KrüGER, Malinche; or, farewell to myths, New York, 1948, pp. 22-23, cita ciertas declaraciones del juicio de residencia de Cortés en las cuales se afirma que doña Marina ya era madre de una hija cuando conoció al conquistador, y que éste tuvo relaciones con dicha hija. García ICAZbalcETa, p. 12, nota 1, acepta lo de la hija pero no lo de las relaciones entre ella y Cortés. Como ejemplo de más fantasía moderna, véase J. Luis Trenti, Grandes mujeres de América, Buenos Aires, 1945, p. 19, el cual niega la existencia misma de doña Marina (cit. por Dalmiro de la Válgoma y Díaz-Varela, Ascendientes y descendientes de Hernún Cortés, Madrid, 1951, p. 5o, nota 85).

29 En efecto, no estuvieron juntos sino dos años durante la conquista (de julio de 1519 a agosto de 1521 ), y sólo intermitentemente durante los tres años siguicntes (hasta octubre de 1524 , cuando doña Marina se casó con Jarami1lo). Martín Cortés, el único hijo conocido, declaró en 1566 tener 40 años, lo cual haria fechar su nacimiento en 1526. Manuel Orozco y Berra, Noticia histórica de la conjuración del Marqués del Valle (años 1565-1568), Puebla, 1853. p. 24, nota 1, hace ver que seguramente Martín se quitaba años, y por consideraciones de lógica sitúa su nacimiento en 1522 o 1523. En esa obra muestra Orozco y Berra la fuerte lealtad de Martín y de otro hijo natural del conquistador, Luis Cortés (nacido de Antonia Hermosilla) para con el Martín Cortés legítimo, hijo de doña Juana y segundo Marqués del Valle durante los años difíciles de la supuesta conjuración.

${ }^{30}$ Mus̃oz Camargo, p. 180. Refiriéndose a esta y a otras afirmaciones parecidas, dice García Icazbalceta, p. 12, nota 乞, que es difícil explicar "de dónde sacó Muñoz Camargo tal máquina de disparates".

31. Illescas, p. 289; Ferviando de Alva Ixílilxóchitl, Décima tercia relación de la venida de los españoles y principio de la ley evangélica [ca. 1608], México, 1938. Sandoval, p. 169, juiciosamente omite lo que aquí dice Illescas, pese a su costumbre de copiarlo en todo.

32 Parte treinta: Comedias escogidas de los mejores ingenios de España, Sevilla, s. a., pp. 13-14. 
Aguilar y doña Marina era lógica y conveniente, por cierto, pero la falsificación histórica es tanto más difícil de sostener cuanto que, según nos hacen saber Cervantes de Salazar (pp. 117-118) y Herrera (t. 4, pp. 322 y 325-326), Aguilar había hecho voto de no casarse nunca, por ser clérigo de órdenes menores. En el poema Mexicana, de Lasso, Aguilar refiere (fol. 3o) que ha mantenido una absoluta castidad a pesar de las muchas tentaciones que se le ofrecieron durante los años que vivió entre los indios.

Son sobre todos los poemas épicos los que callan la relación de amantes que tuvieron doña Marina y Cortés: la presentan a ella como su leal intérprete, y nada más, aunque la pintan como mujer extraordinaria para ser india. Lasso, en la Mexicana (fol. 137), sigue de cerca a Gómara por lo que respecta a su origen, y la presenta en estos términos:

Era donzella apuesta, graue, hermosa; nació en Biluta, de Xalixco aldea, y en vna alteración escandalosa fue hurtada de cierta gente rea. Era de sangre clara, generosa, dada a Cortés por alta y gran pressea ${ }^{33}$.

Muñoz Camargo la declara "hermosa como una diosa", y Solís, muchos años después, la concibe "de buen talle y más que ordinaria hermosura" 34 . El poema $E l$ peregrino indiano, de Saavedra Guzmán ${ }^{35}$, se toma algunas libertades con la relación de Gómara:

porque siendo muy niña fue robada de vn Indio de la tierra Potonchana, y que era de nación Cacica honrada: y a ella y a otra más pequeña hermana criauan, y era gente allá estimada.

Un símil expresa la reacción de Cortés al descubrir cómo Marina le puede servir de intérprete: irradia alegría como el luminoso sol cuando sale de detrás de una nube que lo había ocultado (ibid.).

También truecan algunos el motivo de la verdadera relación entre Cortés y doña Marina, al narrar el descubrimento de la trai-

33 En el Cortés valeroso, fol. 97, lo único que dice Lasso es que la "india cautiva" resolvió el problema de la comunicación con Teudilli, en la costa.

34 Antonio de Solís y Rivadeneyra, Historia de la conquista de México, en $B A E$, t. 28, p. 230. Al parecer, la belleza de doña Marina aumenta con el correr de los años. BANCROFT, t. 1, p. 117, declara que jóvenes y viejos quedaban arrobados por su hermosura, tal como ocurria a quienes veían a Helena de Troya. Gómez ne Orozco, p. 22, concluye que todos los hombres se hacian "esclavos de sus encantos".

35 Antonio de SaAvedra Guzmán, El peregrino indiano, Madrid, 1599 [reimpresión facsímil de México, 1880-81], p. 191. 
ción de Cholula. Cuenta Bernal Díaz (cap. 33: t. 1, pp. 295-296) que Cortés logró extraer confesiones a algunos sacerdotes indios -al estilo de la época, se entiende-, confesiones que se confirmaron cuando una vieja de Cholula invitó secretamente a doña Marina a salvarse de la planeada matanza de los teules españoles, con objeto de que se casara con un hijo suyo que era cacique. Doña Marina se lo participó en seguida muy lealmente a Cortés. Además de todo esto, Gómara (t. 1, p. 19o) había mencionado que la amante india de Pedro de Alvarado le había revelado la conjuración de Cholula aun antes de que los españoles salieran de Tlaxcala. En los poemas -el Cortés valeroso (canto XII) y la Mexicana (canto XX) de Lasso, y El peregrino indiano (canto $\mathrm{X}$ ) de Saavedra- se combinan estos incidentes históricos de una manera novelesca en la que ni siquiera se menciona el papel de doña Marina. Y en La conquista de México de Zárate (pp. 18-20), "Mariana" se entera de la conspiración de Cholula estando ella en la costa, y se lo cuenta a su marido Aguilar, quien en el acto se lo advierte a Cortés por una carta (en la que los indios ven tan sólo unas hormigas negras y mágicas sobre el papel).

Una sola composición en verso une románticamente a Cortés y doña Marina, pero manteniendo puro y sin mancha su amor a pesar de los ardientes deseos mutuos. Cortés triunfante en Tlascala, de Agustín Cordero ${ }^{36}$, es obra concebida dentro de los cánones de la comedia del siglo xvn. En una escena exótica, situada en un templo de los infieles, un sacerdote levanta ya el cuchillo de obsidiana para abrirle el pecho a Marina, cuando irrumpe en el templo Cortés, que mata al sacerdote y salva a la infeliz, librándola de sus ataduras. Ella se pone de pie y, de pronto, los dos se reconocen (p. 3o):

Cortés-Mas ¡qué miro!

Marina- Pero iqué veo!
Cortés- ¿No es ésta...
Marina-¿No es éste... la noble india...,
Cortés-
Marina-el brioso joven...,
Cortés-
Marina-que clemente..., que bella...,
Cortés-
Marina-allá en mi infelice tierra ...

${ }^{36}$ Cádiz, 1780. Hay un ejemplar de esta edición en el British Museum. En la Bibl. Municipal de Madrid he visto tres copias mss., retocadas, y las tres con fecha 1768. Los comentarios de los censores dan a entender que hubo ediciones anteriores. Es probable, pero no seguro, que la comedia sea del siglo xvir (no se sabe nada acerca de Cordero). El dar un papel principal y romántico a doña Marina, frente a Cortés, fue una innovación muy significativa. 
Ella explica que tuvo que huir de su tierra tabasqueña a causa de los insultos que se le hacían por haber servido de medianera entre su gente y los españoles. El conquistador la consuela caballerosamente (p. 32):

India hermosa, ya segura

estás: no habrá quien se atreva, en mi compañía servida, a maltratar tu belleza.

Poco después, ambos encuentran difícil resistir a la mutua inclinación, pero heroicamente lo consiguen (p. 37):

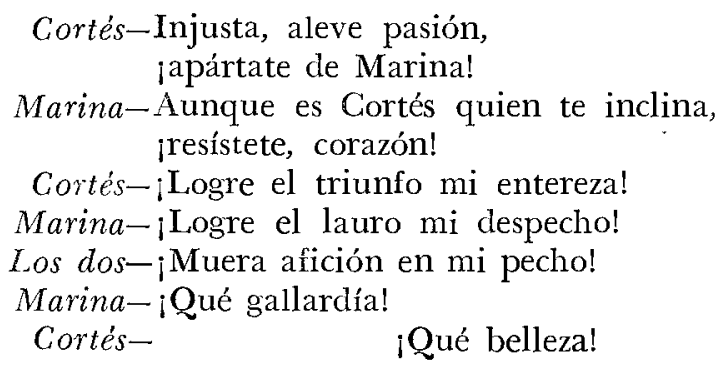

Se descubre providencialmente que doña Marina es hija de Teutemón, cacique de Tabasco, y las últimas palabras de Cortés en la comedia indican que ella está ya definitivamente libre de su pasión y que será la intérprete respetada por la tropa de conquistadores: "Marina irá respetada/entre aparatos marciales, / dando al Exército lustre" (p. 47).

La tendencia a alterar de una u otra manera la verdadera relación entre Cortés y la Malinche creaba un héroe más perfecto y amable para los lectores de poemas y para el público de comedias. Hasta cierto punto, se trata de un artificio literario consciente, pero también refleja la adhesión de todos a Gómara -fuente de los versificadores de la conquista en los siglos xvi y xvn- porque, en rigor, Gómara no presenta a Marina como la amante de Cortés, aunque en una ocasión se refiere de paso a "sus hijos"37.

Por otra parte, el papel realmente dramático que ella tuvo en la conquista de México la ha convertido en una de las amantes más famosas de la historia ${ }^{38}$. Quiérase o no, los mexicanos aún se dan

37 Gómara, t. 2, p. 133. Ya hemos dicho que Martín fue su único hijo reconocido y probablemente el único que tuvieron.

38 Además de las obras arriba citadas cuyo tema central es doña Marina, y prescindiendo de los centenares que la tratan marginalmente al referir la conquista de México, cabe mencionar los estudios siguientes: Federico FerNÁNDEZ DE CASTILlejo, El amor en la conquista: Malintzin, Buenos Aires, 1943; Felipe GonzÁlez Ruiz, Doña Marina (la india que amó a Hernán Cortés), Madrid, 1944 (romántica teorización de que doña Marina fue el único amor 
cuenta, dolorosamente, de su presencia viva en ellos. Cortés será o no el "padre de la nacionalidad mexicana", según los diversos puntos de vista; paralelamente, la Malinche será la querida madre legendaria o el odiado símbolo de la traición que popularmente ha llegado a cuajar en el término malinchismo ${ }^{39}$.

Las letras han concedido una buena medida de inmortalidad a otra amante de Cortés: la princesa Isabel, hija de Moctezuma ${ }^{40}$. E] emperador azteca le dio al conquistador dos o tres hijas, para su "protección íntima"41. Una de ellas murió en la Noche Triste. Otra, bautizada Isabel - pero a veces llamada Inés-, vivió para dejar un linaje ilustre en el México colonial, a través de una hija ${ }^{42}$. Pérez de Villagrá, en su Historia de la Nueva México, hace mención de esa hija de Isabel y Hernán Cortés:

verdadero de Cortés, “su Dulcinea”); Dick Thompson, Doña Marina, Madrid, 1953 (cit. por J. Alcina Franch y J. Palop Martínez, América en la época de Carlos $V$, Madrid, 1958, p. 66). Otros libros hay que tienden más hacia el género de novela histórica: Ireviso Paz, Doña Marina, México, 1883,2 ts.; Haniel Long, Malinche (Doña Marina), Santa Fe, N. M., 1939; Elizabeth Rachel (CANNon) Porter, Cortés the conqueror, his romance with Donna Marina, Philadelphia, 1944; Alexander BaroN [pseudónimo de Alec Bernstein], The golden princess, New York, 1954 .

30 Entre los que afirman, de una u otra manera, el papel de Cortés como "padre de la nacionalidad", cabe mencionar los siguientes: Pereyra, p. 285; José Vasconcelos, Hernán Cortés, creador de la nacionalidad, México, 1941; Esquivel OrRegón, pp. $5^{8}$ y ${ }^{15} 5$; José Elguero, España en los destinos de México, Madrid, 1942, p. 87; y Alfonso Trueba, Hernán Cortés, México, 1954, p. 47. - Sobre el papel de la Malinche dice Bancroft, t. 1, p. 120, nota 6, citando el Anihuac de Rodríguez, p. 461: ". . impressing her memory upon the hearts of the grateful people, over whose welfare she even now watches. Invoked by them, her spirit is frequently encountered in its twilight flights on errands of mercy and consolation, issuing from the ancient groves of Chapultepec, where centres the recollection of Aztec glories. Ballads still perpetuate her virtues, and many a nature's monument bears proudly the beloved name of Malintzin. Tradition also transforms her into a naiad who daily rises from the pool of Chapultepec, singing divinely". -En cambio, el célebre patriota Ignacio Ramírez, en un discurso conmemorativo de la independencia mexicana, pronunciado en 1886 y recogido en sus Discursos y artículos, México, 1917, p. 5, habla indignadamente de cómo sobrevino la perdición de México a causa de "la barragana de Cortés" (cit. por G. A. Ronkíguez, p. 57). Eulalia Guzmán, "Pról." cit., pp. xxi y cxxv, dice que la única herencia de doña Marina es el odioso malinchismo, el complejo de inferioridad racial de México.

40 Es la heroína de dos novelas históricas modernas, por lo menos: HenRY Rider Haggard, Montezuma's daughter, New York, 1893 (reimpresa en 1920), y Sara García Iglesias, Isabel Moctezuma, la última princesa azteca, México, 1946 .

41 BANCROFT, t. 1, p. 312, nota 6, que cita el juicio de residencia y un pasaje de Bernal Díaz.

42 Cf. Gómkz de Orozco, p. 187 , nota 1. La hija se llamó doña Leonor Cortés Moctezuma. 
En cuia hija de unas tres Infantas, que el postrero de todos ellos tuvo, tuvo otra aquel Marqués noble del Valle ${ }^{43}$.

(Se dice que la hermosa Isabel, llamada al parecer Tecuichpo antes de su bautismo, había estado casada brevemente con los sucesores de Moctezuma, es decir, con Cuitláhuac y Cuauhtémoc, y que después de la conquista lo estuvo con cuatro o cinco españoles) ${ }^{44}$.

Se sublima el punto de vista indio en un poema náhuatl muy interesante, el Canto tlaxcalteca acerca de la Conquista, conservado, según se dice, por tradición oral ${ }^{45}$. El anónimo poeta azteca evoca un episodio que transcurre en Coyoacán, nueve días después de la caída de Tenochtitlán. Mientras habla con su amigo Tlacotzin, lamentando la trágica suerte de su imperio, Cuauhtémoc ve de pronto que Isabel está sentada junto a Cortés y comprende que ello simboliza la rendición total de su pueblo al conquistador:

Le responde el rey Cuahtemoctzin:

Oh hermano mío, hemos sido presos, hemos sido engrillados. ¿Quién eres tú la que estás sentada junto al Capitán General?

43 Gaspar Pérez de Villagrá, Historia de la Nueva México, México, 19oo, p. 27. Agrega Villagrá que Cortés casó más tarde a Leonor con Juan de Tolosa ("a quien este Marqués quiso por yerno, / dándole por esposa regalada / a su querida hija y cara prenda”). Pero Gómez de Orozco, p. 187, nota 1, dice de ella: “...casada con el conquistador vizcaíno Joanes de Tolosa contra el parecer de Cortés".

44 Cf. Gómara, t. 2, pp. 221-222; Prescotr, t. 2, p. 339, nota 36, y pp. 192 193; y Rubén García, "La esplendorosa belleza de la emperatriz Tecuichpo..." (véase supra, nota 8). El general García hace la acusación absurda de que Cortés violó a Tecuichpo, y añade que los mexicanos recordarán siempre a esa princesa por su belleza legendaria y sus amores turbulentos, que la ponen en la misma línea que la Güera Rodríguez y la actriz cinematográfica María Félix. Cuando Cortés murió, Isabel estaba casada con el conquistador Juan Cano. Francisco del Paso y Troncoso, Epistolario de Nueva España, ${ }^{2505-I} 8 I 8$, México, 1939-42, publica una "Carta al rey, de Juan Cano, pidiendo que se restituyan a su mujer doña Isabel de Montezuma los bienes que le pertenecían, o se les dieren otros en recompensa (México, $1^{9}$ de diciembre de 1547) "(t. 5, pp. 62-63) y una "Petición presentada por Juan Cano en el Consejo de las Indias sobre que se restituyeran a su mujer los bienes que fueron de su padre" (t. 15, pp. 137-139). El estudio más completo que existe sobre Isabel, basado sobre todo en las peticiones que ella y sus distintos maridos hicieron a la corona, es el de AMAda López de MeNeses, "Tecuichpochtzin, hija de Moteczuma (¿15io-I550?)”, RIM, 9 (1918), 471-498. Según esta historiadora, es poco probable que doña Isabel haya tenido que ver con Cuitláhuac, mientras que su relación con Cuauhtémoc es indudable (p. 472); y dice que, después de la muerte de doña Catalina Juárez, Cortés instaló a Isabel, que acababa de enviudar, en su casa, donde "sin prejuicios raciales, había tenido un verdadero desfile de indias" (p. 475).

${ }_{45}$ Poesia indigena de la altiplanicie, ed. y trad. de Ángel María Garibay K., México, 1952, "Introducción" del editor, pp. vii-xxi. 
Ah, eres tú ciertamente, oh Isabelita, oh sobrinita mía:

jen verdad son entregados los príncipes!

Por cierto serás esclava en lugar cerrado,

se harán joyeles, se tejerán plumas en Coyoacan.

Oh hermano mio, hemos sido presos, hemos sido engrillados.

¿Quién eres tú la que estás sentada junto al Capitán General?

Ah, eres tú ciertamente, oh Isabelita, oh sobrinita mía:

en verdad son entregados los príncipes.

¡En verdad son entregados los príncipes! ${ }^{46}$

Una angustia amarga acompaña esta acusación de traición, en una voz más personal que la que hemos encontrado en el sentimiento adverso a doña Marina. Porque ésta es la sobrina de Cuauhtémoc, si no su mujer, y ella ocupa voluntariamente un puesto de honor al lado del enemigo triunfante. Ya no hay esperanza. Isabelita, aunque agasajada, será esclava del conquistador. El futuro de la raza está ya escrito. El último monarca azteca habla con una tristeza profunda, realzada por el pleonasmo y la reiteración característicos del lenguaje poético náhuatl, que requiere la convergencia de muchos sonido e imágenes para fijar y aclarar un concepto ${ }^{47}$. El mexicano de hoy sigue vertiendo lágrimas desesperadas, expresión subconsciente de la "divina" humillación de sus antepasados. Pero presiente también una angustiada satisfacción, puesto que también es descendiente del conquistador español. La sumisión de Isabel y de doña Marina integra y enfoca la última dimensión de la conquista.

Si se exceptúa el episodio de Cortés e Isabel, concebido al cabo desde un punto de vista no "ortodoxo", los poetas y dramaturgos del Siglo de Oro, tanto en México como en España, alteraron los hechos libremente para moldear la figura del conquistador de acuerdo con los ideales morales reinantes y las exigencias del género en que escribían. En el teatro fue, lógicamente, un galán noble y enamorado que ambicionaba sólo ganar la mano de Juana (El valeroso español y la Comedia de los pleylos), o que virtuosamente domeñó su pasión secreta por Marina (Cortés triunfante en Tlascala), o bien, como leal capitán, sacrificó ese amor para que su compañero Aguilar pudiera casarse con doña Marina (Conquista de México).

Los poemas épicos lo presentaron, sencillamente, por encima de las pasiones mundanas, como el héroe ideal que ejercía un dominio

46 Ibid., p. 62. Una nota de la p. 190 nos hace saber que "Isabelita" traduce el Ixapeltzin del texto náhuatl. Con variantes de estilo, véase otra traducción de Garibay en Visión de los vencidos: Relaciones indígenas de la conquista, ed. M. León-Portilla, México, 1959, p. 196.

47 Véase Josí López Portillo y Weber, "Lo sobrenatural y la conquista de México", Rev. de Estudios Históricos, $2^{\text {a }}$ serie, núm. 1 (1955), p. 11 del apéndice "Cuadernos". 
completo sobre sus instintos ${ }^{48}$. Después de todo, la castidad era uno de los preceptos fundamentales del código de virtud caballeresca ${ }^{49}$. Pero se ha sostenido tradicionalmente que un guerrero, para salir con bien, no debe mezclar el amor con la guerra ${ }^{50}$. Así, en la Gerusalemme liberata de Tasso la encantadora Armida arrastra a su perdición a miles de héroes (canto IV), pero no al incomparable Godofredo, quien se salva gracias a su celestial escudo de altos propósitos (canto V). El hecho es que por la mayoría de los grandes poemas épicos transitan sirenas tentadoras, pero están singularmente ausentes en los poemas cortesianos. Los españoles glorificaron al Cid Campeador por su castidad ${ }^{51}$, pero no hubo Helenas ni Didos que lo tentaran. Cuando se menciona a doña Marina en los poemas, ella no es más que la respetuosa intérprete que colabora en la hazaña trascendental de la conquista, en contraste con los numerosos lances amorosos de los indios nobles y los capitanes españoles.

Nadie quizá fue tan extremado al hablar de la castidad de Cortés como Tirso de Molina en su comedia Todo es dar en una cosa. Guando el enamorado Gonzalo Pizarro le pondera sus sentimientos a su joven amigo Cortés, éste le confiesa que no ha tenido ni experiencia ni interés en el amor (NBAE, t. 4, p. 535):

$$
\begin{aligned}
& \text {... Nunca de amor supe: } \\
& \text { gran cosa debe de ser, } \\
& \text { pues tanto os desasosiega }[\ldots] \\
& \text { ¿qué poco al amor me inclino! }
\end{aligned}
$$

Vicente Palatino de Gurzola ${ }^{52}$, hacia 1559 , ya había definido así a Cortés: "Más casto que Escipión Africano" -frase en verdad sonora, pero no precisamente apegada a la verdad histórica.

Winston A. Reynolds

University of California,

Santa Barbara.

48 Cf. ERnst Robert Curtius, Literatura europea y Edad Media latina, México, 1955, t. 1, p. 242.

49 Cf. Carlos Claverfa, "Notas sobre la caracterización de la personalidad en Generaciones y semblanzas", AUM, 10 (1951-52), p. $5^{02}$ y nota 61 bis, si bien este autor observa que muchos de ios nobles elogiados en la obra de Pérez de Guzmán no se caracterizan precisamente por su castidad.

50 Cf. Daniel Devoto, "El mal cazador", $H D A$, t. 1, pp. 481-491.

a1 Américo Castro, La realidad histórica de España, México, 1954, p. 308.

52 Tratado del derecho y justicia de la guerra que tienen los reyes de España contra las naciones de la India occidental, en el Cuerpo de documentos del siglo xvi sobre los derechos de España en las Indias y las Filipinas, ed. Lewis Hanke, México, 1943, p. 18. 